\title{
Editor's Introduction: Unforeseen Consequences of Policy Decisions
}

\author{
Bobbi S. Low \\ University of Michigan
}

It is almost a truism that populations affect their environment, and that environments constrain populations. Yet as we work to elucidate the actual workings of these interactions, we are often surprised. This issue of Population and Environment focuses on unforeseen or unintended consequences of policy. Often, centralized government policies are specifically directed at affecting people's reproductive lives, or their residences. But even policies not intentionally aimed at population issues such as fertility or migration can nonetheless affect people's lives: their fertility, their mortality, and their movements.

Barbara A. Anderson offers a useful typology of unintended population consequences of policies. She suggests they occur three ways: (1) a policy overshoots its original goal; (2) two or more policies conflict, so that implementation of one policy inhibits implementation of another; (3) negative consequences of a policy are unforeseen, are anticipated but judged unlikely to be severe, or are considered less important than the positive aims of the policy. She discusses diverse examples from Singapore, South Africa, Italy, the United States, and the former Soviet Union.

Catherine O'Connor offers a new perspective on Indonesian forestry decisions, finding that they have significant unexpected effects. In addition

Please address correspondence to Bobbi S. Low, School of Natural Resources and Environment, University of Michigan, 430 East University, Ann Arbor, MI 48109-1115; e-mail: bobbilow@umich.edu 
to previously well-documented negative effects (e.g., environmental degradation and ethnic conflict), Indonesia's central government programs of transmigration and industrial forest management affect indigenous rights, subsistence patterns, and migration, through appropriation of forested land and migrant subsidies. O'Connor argues that Indonesia's programs have undercut their own objectives, interacting synergistically to increase population pressure, reduce available land, and intensify land use conflicts on the outer islands. Now that we recognize these problems, $\mathrm{O}^{\prime}$ Connor suggests that we urgently need empirical evidence to evaluate the interactions between transmigration and forest conversion and to design appropriate management strategies that incorporate local as well as central controls.

Tih-Fen Ting analyses a series of unintended impacts on one of the world's largest populations. The People's Republic of China, during the second half of the twentieth century, has been repeatedly affected by social and political upheavals associated with government policies. These have altered the reproductive costs and benefits of individuals, and as a result, have produced unexpected changes in Chinese demography. Ting examines demographic patterns in Hebei, Shaanxi, and Shanghai (provinces differing in ecology, geography, and economy) as they respond to changes in central government policies. Chinese policies have affected the three populations differentially at both the individual and aggregate levels. She finds not only a general trend, but also important differences that we might call "patterned variation."

The Great Leap Forward and subsequent famine depressed fertility and increased mortality among the largely rural populations of Hebei and Shaanxi; effects were less striking in Shanghai. In contrast, the Cultural Revolution and family planning lowered fertility most among Shanghai women. The population history of China during the second half of last century thus reflects strong state interventions in the lives of its citizens. Government policies, along with regional variations in geographic, social, and economic conditions, strongly influenced individual access to resources in China. Ting's study reveals how variations in the timing and intensity of women's reproductive patterns reflect differential access to resources and subsequent reproductive trade-offs, as central Chinese policies changed.

Ting further analyses how individual families, of different work and educational status, responded to government policies in terms of their investment in children. At any particular resource level, a classic tradeoff exists between number of children and possible per capita investment in children. During the first three decades of the People's Republic of China, income differences across social classes were compressed; formal educa- 
tion was not an important determinant of personal income. Ting's analysis highlights the fact that not only material resources, but also "cultural capital" (knowledge, access to decision-makers, and more) can be transmitted by parents. Ting finds no difference in income between white-collar and blue-collar families, although white-collar parents had more education. In urban China, where population density was high and competition relatively intense, couples' occupational status appeared to affect their trade-offs of quantity and quality of children. Urban white-collar couples had fewer, but better educated, children than their blue-collar counterparts. In rural areas, white-collar couples still had better educated children than blue-collar couples, but they showed no difference in lifetime reproductive success. High population density, and an occupational structure that incidentally helped reinforce unequal distribution of cultural capital across families, appear to have encouraged urban couples to change reproductive strategies, depending on their level of resources, both physical and cultural.

Stephanie Hitztaler finds similarly striking responses, in fertility and migration, to resource changes in three areas of the Kamchatkan Peninsula. She demonstrates a clear relationship between declining population patterns and the widespread socio-economic crisis of the post-Soviet period. There changes are important at several levels. First, the removal of subsidies for forestry reduced resource access; reduced fertility, increased mortality and out-migration followed. But this loss of subsidy interacted with local socio-economic, ecological, and historical conditions in the three localities Hitztaler examined. More dramatic fertility declines, and mortality increases, occurred where the socio-economic crisis coincided with a local natural resource crisis. Further, responses of indigenous and non-indigenous women were similar, but differed in detail: both experienced an increase in very early age-specific fertility and a sharp decline in later fertility (earlier "stopping").

Out-migration increased not only in central Kamchatka, but also throughout the Russian Far East. However, fertility patterns and migration patterns varied among villages in Kamchatka, a rural and resource-dependent area. Villages facing a local natural resource crisis (e.g., where forestry had removed most easily harvested timber) showed greater net negative migration than those with a relatively intact resource base. Hitztaler also argues that historical circumstances influence migration patterns. People's decisions to migrate are clearly complex, and affected by socio-economic, political, ecological, and historical conditions.

In both China and the ex-Soviet Union, state interventions affected citizens' lives. The two nations shared a similar political structure, a similar model of central planning, and the same vision regarding the path to eco- 
nomic development. Both countries also went through a succession of social and political upheavals in the last century. For example, the political, economic, social, and demographic factors leading to the Great Leap Forward and the subsequent famine in China closely resembled factors leading to the 1932-33 famine in the Soviet Union. The impacts of the various social and political events on the two nations' populations were equally dramatic. Women in both countries, confronted with the socio-political dislocations at the start of their reproductive careers, were similarly affected with regard to the timing of marriage and fertility. Nevertheless, among other things, differences in the physical environment and population base led to different population policies for China and the Soviet Union.

In each of the studies in this issue, there are broad predictable patterns, with variation. The particulars differ, but quite robust conclusions emerge. Population patterns are the aggregate outcome of individual and family decisions; and these very local decisions respond to access to resources-both absolute and relative access, and both physical and sociocultural resources. Until we understand these dynamics better, we will continue to be surprised, often unpleasantly. 